\section{Commentary: Patent foramen ovale is not always a benign condition}

\author{
Amedeo Anselmi, MD, PhD
}

In their report, Medina and colleagues ${ }^{1}$ describe an illustrative clinical case in which urgent surgery allowed concomitant excision of a clot-in-transit, closure of a patent foramen ovale (PFO), and pulmonary embolectomy. In the context of massive pulmonary embolism, this operation acquired a life-saving characteristic. Early surgery also allowed uneventful right ventricular recovery after major pulmonary embolism. Several messages can be drawn from this interesting case:

- Think of it: Independent on the severity at presentation, patients with history of concomitant pulmonary and systemic embolism should be promptly evaluated through transesophageal echocardiography to identify a PFO or an atrial septal defect, with or without a clot-in-transit. Such diagnostic step might greatly influence a patient's prognosis.

- Contrary to some belief, PFO is not a truly benign condition, even in absence of prothrombotic status. In fact, PFO remains dynamically patent in about one-fourth of the general population, ${ }^{2}$ it has been associated with cryptogenic stroke in young adults, ${ }^{3}$ and patients with PFO and previous thromboembolism show a yearly stroke risk up to $4.2 \%$ despite anticoagulation. ${ }^{4}$ The finding of a PFO should elicit discussion over research of cryptogenic stroke and consideration of percutaneous

\footnotetext{
From the Division of Thoracic and Cardiovascular Surgery, Pontchaillou University Hospital, Rennes, France.

Disclosures: The author reported no conflicts of interest.

The Journal policy requires editors and reviewers to disclose conflicts of interest and to decline handling or reviewing manuscripts for which they may have a conflict of interest. The editors and reviewers of this article have no conflicts of interest.

Received for publication Aug 30, 2020; revisions received Aug 30, 2020; accepted for publication Sept 5, 2020; available ahead of print Sept 25, 2020.

Address for reprints: Amedeo Anselmi, MD, PhD, Division of Thoracic and Cardiovascular Surgery, Pontchaillou University Hospital, Rennes, France (E-mail: amedeo.anselmi@chu-rennes.fr).

JTCVS Techniques 2020;4:143-4

2666-2507

Copyright (C) 2020 The Authors. Published by Elsevier Inc. on behalf of The American Association for Thoracic Surgery. This is an open access article under the CC BY-NCND license (http://creativecommons.org/licenses/by-nc-nd/4.0/).

https://doi.org/10.1016/j.xjtc.2020.09.004
}

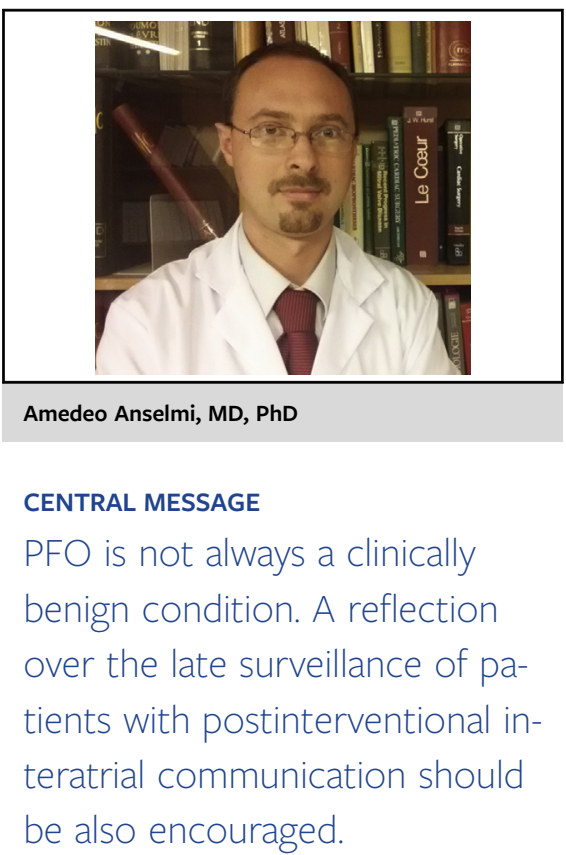

(if isolated) or surgical closure (if concomitant to other cardiac operations).

- As illustrated in the video provided by Medina and colleagues, ${ }^{1}$ a clot-in-transit might be of friable consistency mainly if recently formed. This argues against thrombolysis because it might induce fragmentation or thrombus dislocation from the PFO, thus increasing the likelihood of embolism. Such consideration is in favor of surgery during the decision-making process in such conditions.

The current clinical case depicts an infrequent scenario in a patient with a congenital PFO. Nonetheless, the possibility of clinically relevant paradoxical embolism should be considered in the population of patients receiving mitral valve interventions with a transseptal approach. Transseptal puncture is now performed with a very high degree of intraprocedural safety and reproducibility. But, with increasing the number of recipients of these procedures, and with decreasing their average age, it can be argued that vigilance over clinical or subclinical events related to a persisting iatrogenic interatrial communication is reasonable in the long-term follow-up. As such, percutaneous closure of the transseptal approach might be considered in mitral valve intervention recipients carrying a known prothrombotic status. Nonetheless, such vigilance should not be limited to thromboembolic events. As indicated by clinical experience, progression of right ventricular overload and dysfunction might also occur in some cases as a consequence of 
persisting postintervention interatrial communication. In fact, many recipients of percutaneous mitral interventions have secondary mitral regurgitation in the context of left ventricular dysfunction and increased left ventricular filing pressures, potentially yielding to left-to-right shunt. These patients might be protected from paradoxical embolism, but evolving right ventricular failure might exclude them from other therapeutic strategies in the future. These considerations underline once again the importance of comprehensive and accurate long-term follow-up for the correct appreciation of innovating procedures.

\section{References}

1. Medina M, Guerrero A, Sandoval N, Umana J. Successful surgical treatment of clot in transit with impending paradoxical embolism: a case report. J Thorac Cardiovasc Surg Tech. 2020;4:140-2.

2. Hagen PT, Scholz DG, Edwards WD. Incidence and size of patent foramen ovale during the first 10 decades of life: an autopsy study of 965 normal hearts. Mayo Clin Proc. 1984;59:17-20.

3. Mas JL, Zuber M. Recurrent cerebrovascular events in patients with patent foramen ovale, atrial septal aneurysm, or both and cryptogenic stroke or transient ischemic attack. French study group on patent foramen ovale and atrial septal aneurysm. Am Heart J. 1995;130:1083-8.

4. De Castro S, Cartoni D, Fiorelli M, Rasura M, Anzini A, Zanette EM, et al. Morphological and functional characteristics of patent foramen ovale and their embolic implications. Stroke. 2000;31:2407-13. 